\title{
MIDAS
}

Museus e estudos interdisciplinares

$3 \mid 2014$

Varia e dossier temático: "Museos y participación biográfica"

\section{Projeto LUPA: Laboratório urbano pela arte}

Project LUPA: Urban laboratory through art

\section{Andreia Fernandes, Andrea Monteiro Vicente, Alice Batista e Cláudia} Silva

\section{(2) OpenEdition \\ Journals}

Edição electrónica

URL: http://journals.openedition.org/midas/543

DOI: $10.4000 /$ midas.543

ISSN: 2182-9543

Editora:

Alice Semedo, Paulo Simões Rodrigues, Pedro Casaleiro, Raquel Henriques da Silva, Ana Carvalho

Refêrencia eletrónica

Andreia Fernandes, Andrea Monteiro Vicente, Alice Batista e Cláudia Silva, « Projeto LUPA: Laboratório urbano pela arte », MIDAS [Online], 3 | 2014, posto online no dia 27 maio 2014, consultado no dia 30 abril 2019. URL : http://journals.openedition.org/midas/543; DOI : 10.4000/midas.543

Este documento foi criado de forma automática no dia 30 Abril 2019

\section{(c) (i) (2)(2)}

Midas is licensed under a Creative Commons Attribution-NonCommercial-ShareAlike 3.0 International License 


\title{
Projeto LUPA: Laboratório urbano pela arte
}

\author{
Project LUPA: Urban laboratory through art
}

Andreia Fernandes, Andrea Monteiro Vicente, Alice Batista e Cláudia Silva

\section{Introdução}

1 Partindo do conceito de «espaço público de educação» de Nóvoa (2009), que defende que a escola e a sociedade são responsabilizadas de forma compartida pela educação, como um cenário de evolução desejável para os sistemas educativos. Este cenário exige da sociedade a capacidade de assumir funções que a escola inevitavelmente tem assumido, por falta de outras respostas sociais. Contudo, será a sociedade capaz de assumir estas funções?

2 Apesar da formação cultural e escolar ter aumentado significativamente nas últimas décadas e ser cada vez mais homogénea entre gerações, tornando este cenário verosímil, não significa que a sociedade esteja preparada e tenha a intenção de cumprir com esta tarefa. Se temos que organizar o presente de acordo com a ideia de futuro, somos confrontados com a questão, qual o sistema educativo deste futuro? Se considerarmos a utopia, na perspetiva sociológica, como um plano de mudança social e se esta utopia responde aos desafios da educação do futuro, apresentando-se como o caminho, então trabalhemos para a tornar realizável, gradualmente formemos a sociedade e preparemos a escola para a partilha de responsabilidades, para a diferença e a mudança, para uma nova conceção de aprendizagem e para o reforço do espaço público da educação.

Neste contexto surge o projeto de serviço educativo LUPA - Laboratório Urbano Pela Arte que se apresenta. Esta denominação reflete a essência do mesmo. O LUPA é um projeto de serviço educativo de natureza experimental, não formal, de índole voluntária e sem orçamento, dirigido essencialmente à comunidade da cidade de Castelo Branco. Pretende através da educação pela arte refletir sobre a relação entre a cidade enquanto espaço 
físico e a comunidade enquanto espaço social, com a premissa de que a cidade é o ponto de partida para a promoção, exploração e construção de identidade urbana, reforçando a empatia com a cultura e com as artes, e espaços: laboratórios de partilha, experimentação e criação.

\section{Justificação}

4 A consciência do estado atual do ensino artístico em Portugal e, em simultâneo, a constatação da crescente desertificação humana na zona histórica da cidade de Castelo Branco leva à necessidade de levantamento e análise da oferta de programação cultural disponível, procurando identificar lacunas e desarticulações entre a oferta existente e a comunidade.

5 No seguimento desta análise verificou-se que apenas dois equipamentos se reconhecem como serviços educativos e culturais presentes no dia a dia dos albicastrenses: o Cine Teatro Avenida, que tem feito um trabalho de excelência nos últimos anos, direcionado ao público adulto e a Biblioteca Municipal de Castelo Branco, que tem vindo a trabalhar o público jovem, diariamente, com diversas atividades que envolvem as escolas, as crianças e as famílias. Aos restantes equipamentos não se reconhecem atividades regulares, apenas algumas pontuais, à exceção do Museu Cargaleiro e do Museu Francisco Tavares Proença Júnior que apresentam atividades que denunciam a preocupação em construir um serviço educativo eficiente que responda às necessidades dos seus públicos.

6 No entanto, verifica-se um desequilíbrio entre o crescente investimento em equipamentos culturais, os serviços educativos prestados pelos mesmos e os hábitos de consumo culturais da comunidade. Apesar do visível crescimento cultural e da existência de equipamentos culturais variados e suficientes para a dimensão da cidade, os hábitos de consumo de cultura mantém-se baixos, justificados em parte, pelo constante aumento do desemprego e consequente baixo poder de compra. Os serviços educativos são, no geral, escassos e limitados, verificando-se um baixo investimento em recursos humanos qualificados.

7 Por outro lado, o diálogo entre as instituições culturais é escasso, o que redunda numa sobreposição de eventos de relevância cultural que dificulta a construção de uma programação assertiva.

8 Assim sendo, a análise efetuada foi o ponto de partida para a estruturação e fundamentação deste projeto que pretende ser um serviço educativo que colmate as lacunas identificadas, focando-se na construção de uma rede cultural apoiada em laboratório parcerias e que recorre à cidade enquanto sala de aula privilegiada.

\section{LUPA}

9 O acrónimo LUPA pretende traduzir a essência do projeto: laboratório urbano pela arte. Laboratório porque as atividades propostas são de natureza experimental, na perspetiva em que cada laboratório apela à observação e à descoberta, desenvolvendo estratégias para a resolução de problemas; urbano porque o ponto de partida para a criação destes laboratórios é a construção de identidade urbana, pela promoção de interação social a que lhe é inerente a responsabilidade educativa, assim como pela experienciação sensorial da cidade enquanto espaço físico, na partilha de conhecimento sobre o património material e 
imaterial; pela arte, porque se pretende que os laboratórios criados assentem sobre a teoria da educação pela arte, defendida por Read (2010), em que as artes são mediadoras do desenvolvimento holístico do ser humano.

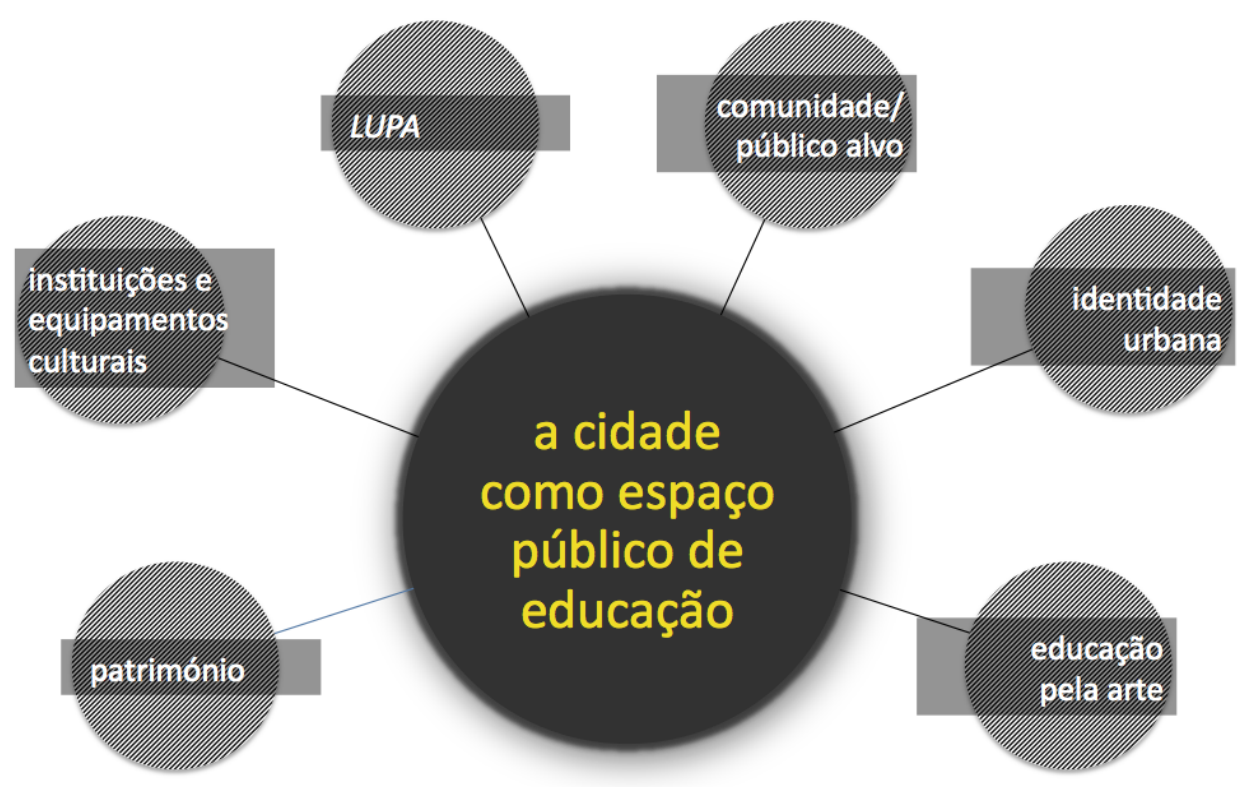

FIg. 1 - DiAgRAMA REPRESENTATIVO dA CONVERgÊNCIA DE CONCEITOS COM O ESPAÇO PÚBLICO EDUCATIVO DO PROJETO LUPA

\section{Missão e objetivos}

10 A missão do LUPA consiste na promoção da construção de identidade urbana, através do saber observar, da experiência e da partilha, trabalhando o público a partir dele próprio. Este projeto pretende potenciar a articulação entre as necessidades, interesses e quereres da comunidade, no contexto cultural, e uma rede organizada de contatos e parcerias institucionais. Por conseguinte, o LUPA passa a ser um meio para atingir os fins: os mediadores/orientadores dos laboratórios promovem a criatividade e a partilha intergeracional e multicultural; os laboratórios laboram na transdisciplinaridade das áreas académicas, da educação e da comunidade.

«O conhecimento é o resultado da relação entre aquele que conhece e aquilo que é conhecido» (Silva 2007, 60). Esta frase reflete, de forma muito sucinta, a missão educativa deste projeto. Os laboratórios LUPA desenvolvem-se sobre a noção sócio construtivista de aprendizagem de Piaget, na qual a construção ativa de conhecimento se baseia num processo social de partilha de conhecimentos, sobre o que se conhece e o que se aprende, relacionando-o ao objeto e ao contexto em que se desenvolve a aprendizagem (cit. por Woolfolk 2000, 244-369). Neste sentido, o serviço educativo permite o desenvolvimento da arena cultural nas suas múltiplas manifestações criativas, colocando-as ao serviço de toda a comunidade como instrumentos de reflexão, mudança e intervenção. Podemos, assim, definir como missão do LUPA a construção de identidade urbana, através de um processo de educação não formal assente na transdisciplinaridade entre a cidade e a comunidade, que permite consolidar uma visão sobre a cultura e sobre as artes, expressando novas perspetivas e formas de aquisição de conhecimento e de compreensão de processos criativos. 
12 O LUPA é um projeto único na cidade de Castelo Branco, que se propõe estimular a descoberta de novos olhares sobre a cidade, explorando capacidades: criativa, artística, de iniciativa, de partilha, de diálogo e promovendo o relacionamento interpessoal e cooperativo. Para o efeito, foram definidos os seguintes objetivos:

- incentivar a construção de identidade urbana, vinculando a comunidade ao seu património (material e imaterial);

- construir conhecimento através da experimentação e da cooperação, explorando competências artísticas;

- formar o indivíduo, respeitando a sua singularidade, para a construção de uma relação de empatia, identificação e cooperação com a cidade, espaço físico e social e, consequentemente, com o projeto;

- trabalhar para a resolução de problemas, estimulando a criatividade e a autonomia;

- dinamizar o envolvimento das comunidades nos projetos culturais e artísticos, estimulando a participação dos albicastrenses e das organizações culturais locais;

- contribuir para que a cultura e o conhecimento se afirmem como dimensões estruturantes do desenvolvimento local;

- promover a difusão das artes e ampliar o acesso da comunidade à fruição e criação culturais;

- captar, formar e fidelizar públicos;

- favorecer a coesão social através da educação pela arte e pela cultura;

- constituir-se como espaço de cooperação e diálogo cultural entre os parceiros e com outras redes e organizações culturais, promovendo e preservando a diversidade cultural;

- garantir a rentabilização de recursos de forma a garantir a autossustentabilidade do LUPA;

- contribuir para a criação de emprego no setor cultural, dentro ou fora do LUPA.

\section{Operacionalização}

13 O LUPA é um projeto probatório no primeiro ano e organiza-se em 12 atividades/ laboratórios de periocidade mensal. Estes laboratórios pretendem (re)conhecer/ (re)valorizar o património material e imaterial albicastrense, através das várias expressões artísticas, nomeadamente, a fotografia, o vídeo, o desenho, as artes plásticas, a arquitetura, o design gráfico e multimédia, a escrita, entre outros. Utiliza ferramentas multimédia, de que são exemplo o software para edição de imagem, o vídeo e o som, a infografia, a modelação 3D ou ferramentas para as artes gráficas e plásticas, de uma forma geral.

14 Todos os laboratórios têm dois pontos em comum. O primeiro, mais importante, tem como ponto de partida e fonte de inspiração a cidade de Castelo Branco nas suas mais variadas perspetivas: a história; as gentes; os jardins; as árvores; os canteiros; a paisagem; o urbanismo; a arquitetura; a calçada; a escultura e arte pública; os artistas visuais albicastrenses; o artesanato; o folclore; os cantares; as romarias; as feiras; as festas; a literatura; a tradição oral; ou seja, o património e a cultura da comunidade albicastrense. O segundo é a utilização das artes como condutoras para a conceção dos laboratórios, o que expressa o contexto teórico que o fundamenta, a educação pela arte.

Para a operacionalização do projeto é relevante ter em conta três dimensões, nomeadamente: a identificação do público-alvo; a formalização de parcerias e/ou redes de contactos enquanto fontes de informação/formação/impulso e criação de novos projetos; e a avaliação. 


\section{Público-alvo}

16 Numa primeira abordagem, podemos considerar que o público-alvo é toda a comunidade albicastrense, pois o objetivo do LUPA é dotar a comunidade de novos conhecimentos e competências relacionadas diretamente com o património material e imaterial da cidade. Mas dizer que é um serviço para toda a comunidade é muito lato. Na verdade, prevê-se o público-alvo, de acordo com os laboratórios programados, fazendo-se aí, a distinção do público ao qual se adequaria melhor a programação e com o qual se gostaria de trabalhar e, evidentemente, como. Tendo em conta que o objetivo é fidelizar este público ao projeto para se obterem as mais-valias esperadas, o que verdadeiramente interessa é que a programação seja direcionada a segmentos de público em função de interesses comuns que podem, ou não, residir entre faixas etárias ou grupos específicos se assim se sentir a necessidade disso.

\section{Parcerias e redes de contatos}

17 As parcerias são pontes entre instituições culturais e a realidade exterior, fortalecem a amplitude do trabalho que a instituição desenvolve, ao mesmo tempo que incrementam o contacto com parceiros cujos objetivos, interesses e perspetivas são comuns, disponibilizando-se, deste modo, a partilhar recursos e/ou estratégias.

São inúmeras as vantagens de se trabalhar em parceria, que pode não só passar pelo reconhecimento público, privado e institucional, mas também pela consolidação de relações importantes para o desenvolvimento de estratégias de sucesso, pelo aconselhamento e engrandecimento de projetos, derivado da troca de experiências entre os parceiros, pela possibilidade de formar equipas mais competentes, pela redução de custos a vários níveis, pelo financiamento ou mecenato mais facilitado na conceção e na produção de recursos, tanto materiais como humanos, pela cedência de espaços e logística da instituição, entre outros.

Não é só de acordo com estes princípios que o LUPA se rege, ou seja, as parcerias que este projeto ambiciona concretizar passam por parcerias com outras instituições, mas também com indivíduos, que pelas suas competências são elementos que podem trazer mais-valias para o projeto. Daqui podemos retirar que a programação e planificação está diretamente relacionada com as parceiras que este projeto concretiza.

\section{Avaliação}

Por ser construído ao longo do tempo e por conseguinte nunca fechado, qualquer projeto deve ser avaliado regularmente, podendo ser alterado sempre que se detetem falhas, ou pontos menos claros, passíveis de ser melhorados. As ações externas ao projeto ou até mesmo as ações decorrentes dentro da instituição que promove o projeto podem sofrer alterações imprevistas. Estes fatores determinam a importância da avaliação tanto interna como externa de um projeto, fixando-se assim, como objetivo máximo da avaliação, a melhoria do projeto no seu decurso. A avaliação é indispensável na medida que produz informação em torno dos resultados dos laboratórios. Sustenta a reflexão sobre os procedimentos, melhora a qualidade do projeto e apresenta resultados concretos 
e assertivos, podendo até ser mensuráveis (dependendo dos laboratórios) que auxiliarão para verificar o valor e a eficácia do plano elaborado e dos laboratórios criados.

21 A avaliação foi definida no momento da preparação do plano de ação educativa, de acordo com os critérios, os objetivos gerais e o cronograma de atividades definidos pela equipa responsável. Neste contexto não se adotou um único modelo de avaliação, tendo em conta que os laboratórios diferem entre si nos objetivos específicos, na estrutura e no públicoalvo.

\section{Reflexão}

As instituições culturais são elementos fundamentais para a construção das representações e identidades das comunidades e marcas importantes desta vitalidade criativa, uma vez que têm a capacidade de gerar, promover e refletir a diversidade, o potencial criativo, o dinamismo e a transformação permanentes que caracterizam o crescimento e evolução das sociedades. Em termos de paradigma de referência, nas últimas décadas, temos vindo a caminhar da Sociedade da Informação para a Sociedade do Conhecimento e da Aprendizagem, e, mais recentemente, da Criatividade. A crescente associação da criatividade ao conhecimento reforça a importância e a transversalidade do pensamento criativo. (Silva 2008, 15)

Os serviços educativos, enquanto espaços de negociação e discussão participada, consideram-se, assim, essenciais na promoção da consciência de que o conhecimento, a aprendizagem e a criatividade desenham o caminho para a construção de identidade das comunidades e da captação e fixação de públicos.

Elaborar um projeto como o LUPA, que pretende ser um projeto fundamentado no conceito de serviço educativo, tem as suas dificuldades. É um projeto inovador, porque não é aplicado a uma instituição cultural, mas sim a toda uma cidade, com tudo aquilo que a cidade pode oferecer. Não tem um espaço físico sede, pois a mesma é a cidade. Por outro lado, é uma iniciativa sem orçamento.

É uma experiência que tem como objetivo analisar o feedback do público e tem uma programação trimestral que depende da análise de propostas elaboradas, pela equipa organizadora e pela comunidade, para novos laboratórios. Todos estes fatores não são fatores de segurança para um projeto mas, laboratório a laboratório, o projeto constrói-se e toma forma. Neste momento, é ainda difícil entender o seu rumo, mas esse é o desafio ao qual a equipa do LUPA se propôs.

\section{BIBLIOGRAFIA}

AA.VV. 2002. Educação e Transdisciplinaridade II. São Paulo: UNESCO.

Barriga, Sara, e Susana Gomes da Silva, ed. 2007. Serviços Educativos na Cultura. Coleção Públicos 2. Lisboa: Setepés. http://www.slideshare.net/JDLIMA/coleco-pblicos-servios-educativos. 
Barros, Sebastião Amoêdo. 1997. A Resiliência da Cultura. Universidade Federal do Rio de Janeiro. http://bocc.ubi.pt/pag/barros-amoedo-Resiliencia-Cultura.html.

Bonet, Lluís, et al., eds. 2010. Políticas para la Creatividad. Guía para el Desarrollo de las Industrias Culturales y Creativas. Paris: UNESCO. http://www.unesco.org/new/fileadmin/MULTIMEDIA/HQ/ CLT/images/UNESCOCulturalandCreativeIndustriesguide_01.pdf.

Botas, Ana. 2013. Recensão de Os Museus e o Património Cultural Imaterial: Estratégias para o Desenvolvimento de Boas Práticas, de Ana Carvalho. MIDAS. http://midas.revues.org/292.

Byrnes, William. J. 2009. Management and the Arts. 4. ${ }^{\text {a }}$ ed. Oxford: Elsevier.

Chong, Derrick. 2002. Arts Management. London e New York: Routledge.

Colbert, François, Jacques Nantel, e Suzanne Bilodeau. 2000. Marketing Culture and the Arts. 2. ${ }^{\mathrm{a}}$ ed. Montréal: Morin.

Decreto-Lei n.․50/2011 de 8 de abril, Ministério da Educação, Diário da República, $1 .^{\mathrm{a}}$ série, n.ำ 70 (2011). http://www.gave.min-edu.pt/np3content/?newsId=31\&fileName=DL_50_2011_08_04.pdf Drucker, Peter F. 1986. Management: Tasks, Responsibilities, Practices. New York: Truman Talley Books - E.P. Dutton.

Freitas, Neli Klix e Janaína de Abreu Pereira 2007. "Necessidades Educativas Especiais, Arte, Educação e Inclusão.” Revista e-Curriculum 2 (2). http://www.redalyc.org/articulo.oa?id=76620203

Gomes, Rui Telmo, e Vanda Lourenço. 2009. Democratização Cultural e Formação de Públicos: Inquérito aos "Serviços Educativos" em Portugal. Observatório das Atividades Culturais. http://www.oac.pt/ pdfs/OBS_Pesquisas15_impressao.pdf.

Nóvoa, António. 2009. “Educación 2021: Para una Historia del Futuro.” Revista Iberoamericana de Educación 49. http://www.rieoei.org/rie49a07.htm.

Read, Herbert. 2010. Educação pela Arte. 3. e ed. Lisboa: Edições 70.

Silva, Susana Gomes da. 2006. "Museus e Públicos: Estabelecer Relações, Construir Saberes." Revista Turismo e Desenvolvimento 161-167.

Silva, Susana Gomes da. 2007. "Enquadramento Teórico para uma Prática Educativa nos Museus." In Serviços Educativos na Cultura, editado por Sara Barriga, e Susana Gomes da Silva, 57-66. Coleção Públicos 2. Lisboa: Setepés. http://www.slideshare.net/JDLIMA/coleco-pblicos-servioseducativos.

Silva, Susana Gomes da. 2008. "Serviços educativos. Espaços de Negociação na Arena Cultural." Boa União - Revista de Artes e Cultura do Teatro Viriato 1 (2): 32-35. http://www.teatroviriato.com/ fotos/editor2/boauniao_2008.pdf.

Woolfolk, Anita E. 2000. Psicologia da Educação. Porto Alegre: Artmed.

\section{RESUMOS}

Em «Educación 2021: Para una Historia del Futuro», Nóvoa introduz o conceito de "espaço público de educação». Um cenário onde a escola e a sociedade são responsabilizadas de forma compartida pela educação. Neste contexto surge o projeto de serviço educativo LUPA Laboratório Urbano Pela Arte que apresentamos neste texto. Trata-se de um projeto de serviço educativo de natureza experimental, não formal, de índole voluntária e sem orçamento, que é 
dirigido essencialmente à comunidade da cidade de Castelo Branco. Pretende através da educação pela arte refletir sobre a relação entre a cidade enquanto espaço físico e a comunidade enquanto espaço social, com a premissa de que a cidade é o ponto de partida para a promoção, exploração e construção de identidade urbana, reforçando a empatia com a cultura e com as artes e construindo espaços - laboratórios de partilha, experimentação e criação. Projeto probatório no primeiro ano, organiza-se em 12 atividades/laboratórios de periocidade mensal, que pretendem (re)conhecer/ (re)valorizar o património material e imaterial albicastrense. A partir da análise da oferta educativa e cultural e do diagnóstico e identificação das lacunas existentes, constrói-se o projeto experimental, na definição de objetivos, na planificação flexível de ações e na construção de metodologias assertivas que estimulem parcerias entre instituições culturais e educativas.

In 'Educación 2021: Para una Historia del Futuro', Nóvoa introduces the concept of public space for education, a scenario in which school systems and societies share responsibility for education. The educational project LUPA originated in this context - a volunteer-led, non-formal educational service of an experimental nature, without funding and without a budget, directed primarily to the community of Castelo Branco. Through education through art it aims to reflect upon the relationship between the city as a physical space and the community as a social space, with the premise that the city is the starting point for the promotion, operation and construction of urban identity, underscoring the value of empathy with culture and arts, and building spaces which function as laboratories to share, experience and create. This project, still in its first year, is organized into monthly activities/labs, that intend to (re)known/(re)value the tangible and intangible heritage of Castelo Branco, or albicastrense. Starting with an analysis of the educational and cultural offer in the region, and the diagnosis and identification of missing elements, an experimental project is set up, its goals and flexible actions following assertive methodologies that encourage partnerships between cultural and educational institutions.

\section{ÍNDICE}

Keywords: cultural heritage, educational project, art education, mediation, learning Palavras-chave: património cultural, projeto educativo, educação artística, mediação, aprendizagem

\section{AUTORES}

\section{ANDREIA FERNANDES}

É licenciada em Design de Cerâmica e Vidro (2009). Tem formação em técnicas de produção de vidro soprado e em fusão de vidro (2009). É professora do 2. e 3.ำ ciclos e secundário e mestre em Ensino das Artes Visuais no 3.ำ ciclo do Ensino Básico e no Ensino Secundário (2013). andreiafernandes88@gmail.com

\section{ANDREA MONTEIRO VICENTE}

É licenciada em arquitetura pela Universidade do Porto (1999), tendo sido monitora da unidade curricular de Projeto III (1998-1999). Atualmente, é doutoranda em arquitetura na Universidade da Beira Interior, Departamento de Engenharia Civil e Arquitetura. Docente neste departamento na unidade curricular de orientação tutorial de Projeto IV/2 e bolseira de investigação da Faculdade de Engenharia no ano lectivo 2012-2013. Finalista no mestrado em Ensino das Artes Visuais no 3.ำ ciclo do Ensino Básico e no Ensino Secundário (2014) na mesma universidade. andrea.vicente@yahoo.com 


\section{ALICE BATISTA}

Licenciada em Ensino Básico (2003) e Design de Comunicação e Produção Audiovisual (2007). É docente profissionalizada no Ensino Básico desde 2003, tendo sido professora do 2.ํ e 3.․ ciclos, entre 2008 e 2011. Mestre em Ensino das Artes Visuais no 3.ํㅜㄷㅇo do Ensino Básico e no Ensino Secundário (2013). Tem formação em fotografia e desenvolve projetos nessa área e em vídeo. cbe.cila@gmail.com

\section{CLÁUDIA SILVA}

Bacharelato em Design e Tecnologia das Artes Gráficas na Escola Superior de Tecnologia do Instituto Politécnico de Tomar (1998) e licenciatura no mesmo curso (2005). Pós-graduação em Produção e Gestão de Espetáculos (2006) e mestrado de Gestão Cultural (2007), ambos na Universidade de Barcelona. Entre 2010 e 2011 lecionou a disciplina de Educação Visual e Tecnológica no âmbito do 2. ciclo do ensino básico em Idanha-a-Nova. Mestre em Ensino das Artes Visuais do 3.ำ ciclo e Secundário na Universidade da Beira interior (2013).

claudia.nunes.silva@gmail.com 